\title{
THE IMPACT OF GLOBALIZATION ON HUMAN RESOURCES
}

\author{
Popescu, L.; Popescu, V. \& IANCU, A.
}

Abstract: Globalization may be considered a form of the competitive advantage that can be achieved by an organization by extending its activity to a global level. It is a continuous process, that can be characterized by the following particularities: the development of foreign investments, the amplification of export activities and the initiation of some international strategic alliances, in order to extend the companies' activities on new markets.

In the context of businesses internalization, the human resources hold a key role, being considered a "strategic partner" that might influence decisively the multinational companies' development and extension strategy, at central level as well as subsidiaries are concerned.

The globalization of markets and businesses has determined the amplification of the human resources function's role in the organizations, fact that imposes an enhanced attention given to the elaboration of some human resources strategies, integrated in the organization's global strategy, permitting the training of managers at international level.

Key words: human resource, globalization, manager, multinational company, international management
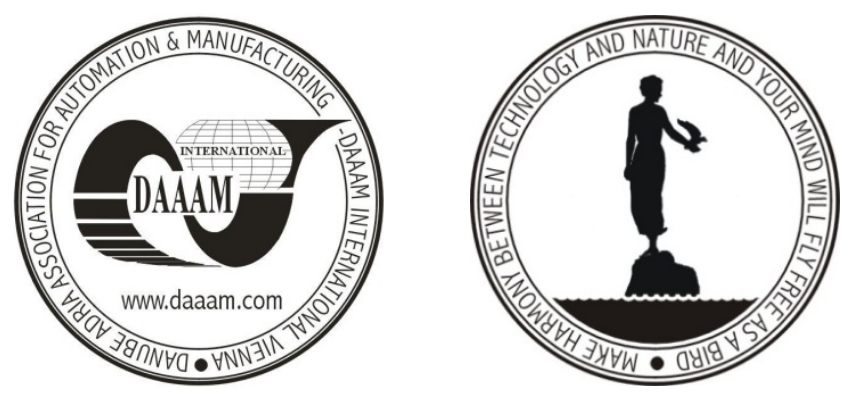

Authors' data: Lecturer PhD. Popescu, L[uminita]; Lecturer PhD. Popescu, V[irgil]; Iancu, A[nica], University of Craiova, Calugareni No.1, 220037, Drobeta Turnu Severin,RO, lumi@mail.expert.ro,virgil@expert.ro, iancunina@yahoo.com

This Publication has to be referred as: Popescu, L[uminita]; Popescu, V[irgil] \& Iancu, A[nica] (2008). The Impact of Globalization on Human Resources, Chapter 53 in DAAAM International Scientific Book 2008, pp. 621-628, B. Katalinic (Ed.), Published by DAAAM International, ISBN 978-3-901509-66-7, ISSN 1726-9687, Vienna, Austria

DOI: $10.2507 /$ daaam.scibook.2008.53 